\title{
1-Aminocyclopropanecarboxylic acid (ACPC) produces procognitive but not antipsychotic-like effects in rats
}

\author{
Piotr Popik • Malgorzata Holuj • Agnieszka Nikiforuk • \\ Tomasz Kos • Ramon Trullas • Phil Skolnick
}

Received: 10 July 2014 / Accepted: 29 August 2014 / Published online: 27 September 2014

(C) The Author(s) 2014. This article is published with open access at Springerlink.com

\begin{abstract}
Rationale In addition to the negative and positive symptoms of schizophrenia, cognitive deficits, including prefrontal cortical dysfunction, are now recognized as core features of this disorder. Compounds increasing the NMDA receptor function via the strychnine-insensitive glycine receptors have been proposed as potential antipsychotics. Depending on the ambient concentrations of glutamate and glycine, 1aminocyclopropanecarboxylic acid (ACPC) behaves as either a partial agonist or a functional antagonist at the strychnineinsensitive glycine receptors.

Objectives We investigated the procognitive and antipsychotic-like effects of ACPC in rats treated with phencyclidine (PCP) or ketamine (KET), compounds that produce psychotic-like symptoms in humans and laboratory animals. Methods Cognitive effects were investigated in the novel object recognition (NOR) and attentional set-shifting tests (ASST). In addition, the effects of ACPC were investigated in PCP-induced hyperactivity, conditioned avoidance response (CAR), and prepulse inhibition (PPI) tests. The effects on attention and impulsivity were measured in the five-choice serial reaction time task (5-CSRTT).

Results ACPC (200-400 mg/kg) inhibited memory fading in naive rats and like clozapine prevented PCP- and KET-
\end{abstract}

P. Popik $(\bowtie) \cdot$ M. Holuj · A. Nikiforuk $\cdot$ T. Kos

Behavioral Neuroscience and Drug Development, Institute of Pharmacology, Polish Academy of Sciences, 12 Smetna Street, 31-343 Kraków, Poland

e-mail:nfpopik@cyf-kr.edu.pl

R. Trullas

Institut d'Investigacions Biomèdiques August Pi i Sunyer, IDIBAPS-CSIC, 08036 Barcelona, Spain

P. Skolnick

Division of Pharmacotherapies \& Medical Consequences of Drug

Abuse, NIDA, NIH, Bethesda, MD 20892-9551, USA induced amnesia in the NOR. In naive animals, ACPC at 400 but not $200 \mathrm{mg} / \mathrm{kg}$ enhanced cognitive flexibility in the ASST, as the animals required fewer trials to reach the criteria during the extra-dimensional phase. In contrast, ACPC did not affect PCP-induced hyperactivity, CAR, and PPI as well as attention and impulsivity in the 5-CSRTT.

Conclusion The present study demonstrates that ACPC enhanced both object recognition memory and cognitive flexibility dependent on the prefrontal cortex, but did not affect impulsivity nor exhibit an antipsychotic-like profile.

Keywords 1-Aminocyclopropanecarboxylic acid - ACPC . Strychnine-insensitive glycine/NMDA site $\cdot$ Learning

Memory $\cdot$ Cognitive flexibility $\cdot$ Attentional set-shifting test . Schizophrenia $\cdot$ Animal models $\cdot$ Prefrontal cortex .

Attention · Impulsivity · Five-choice serial reaction time task (5-CSRTT)

\section{Introduction}

Glutamatergic transmission through the $N$-methyl-D-aspartate receptor (NMDAR) receptor subtype plays a critical role in neuroplasticity. Furthermore, it has been suggested that an increase in NMDAR activity may lead to cognitive enhancement (Danysz and Parsons 1998). Augmentation of glutamatergic neurotransmission may also produce antipsychotic effects; for a review, see Hashimoto et al. (2013). Conversely, NMDA antagonists such as phencyclidine (PCP) and ketamine (KET) elicit positive, negative, and cognitive psychoticlike symptoms in normal volunteers and produce a recrudescence of psychotic symptomatology in patients (Javitt and Zukin 1991; Krystal et al. 1994; Jentsch and Roth 1999).

Activation of the NMDAR requires binding of both glutamate and its co-agonist, glycine, a small nonessential amino acid (Johnson and Ascher 1987). Since an enhancement of 
glutamatergic tone by direct (orthosteric) NMDA receptor agonists does not appear to be a feasible therapeutic strategy, a more practical approach is to enhance the function of strychnine-insensitive glycine sites. This can be done using full and partial glycine agonists or by enhancing glycine availability at the synaptic cleft by inhibiting reuptake through glycine transporter 1 (GlyT1; (Raiteri and Raiteri 2010)). The rationale for this approach relies on the assumption that strychnine-insensitive glycine sites at the NMDAR are not saturated under physiological conditions (for a review, see (Danysz and Parsons 1998)).

Consistent with this approach, both antipsychotic and procognitive effects have been demonstrated for compounds increasing transmission at glycine sites. Almost 30 years ago, glycine itself was shown to reduce PCP-induced hyperactivity in mice (Toth and Lajtha 1986). GlyT1 inhibitors that elevate ambient glycine concentrations reversed or attenuated NMDAR antagonist-induced abnormally persistent latent inhibitions (Lipina et al. 2005; Black et al. 2009) and deficits of prepulse inhibition (PPI) (Lipina et al. 2005; Depoortere et al. 2005; Boulay et al. 2008). In the latter paradigm, the NMDA receptor antagonist ketamine dose-dependently reduces PPI (Swerdlow et al. 1998). While the prototypic antipsychotic haloperidol is inactive per se and does not reverse ketamineinduced reduction of PPI, chlorpromazine, seroquel, and clozapine are active in this model. In general, reversal of NMDA antagonist-induced decreases in PPI is considered an antipsychotic-like effect (see Geyer et al. (2001) for the review).

Other studies demonstrated that D-serine, a full agonist at the strychnine-insensitive glycine sites, enhanced social memory in rats (Shimazaki et al. 2010) and that D-cycloserine, a partial agonist at the strychnine-insensitive glycine sites, facilitated learning and memory in rats (Monahan et al. 1989). Inhibitors of GlyT1 have also demonstrated procognitive effects in preclinical models of schizophrenia. For instance, SSR-103800 reversed PCP-induced impairment of shortterm episodic-like memory in the object recognition task (Boulay et al. 2008), whereas NSFP improved dizocilpine (MK-801)-disrupted social memory (Shimazaki et al. 2010). Recent data from this laboratory (Nikiforuk et al. 2011) demonstrated that SSR-504734, a non-sarcosine GlyT1 inhibitor, enhanced cognitive performance in the attentional set-shifting test (ASST), a measure of prefrontal flexibility that is compromised in schizophrenic patients (Lewis and GonzalezBurgos 2008) as well as in healthy volunteers (Krystal et al. 1994) and rats treated with NMDAR antagonists (Stefani et al. 2003; Egerton et al. 2005; Nikiforuk et al. 2010).

In clinical studies, glycine (Javitt et al. 1994), D-serine, and sarcosine have been shown to ameliorate symptoms of schizophrenia in medicated patients (Lane et al. 2005; Tsai and Lin 2010). Meta-analyses indicate that glycine, D-serine, and sarcosine are more effective than D-cycloserine in improving the overall psychopathology in schizophrenic patients receiving antipsychotic drugs (Heresco-Levy and Javitt 2004; Tuominen et al. 2005; Tsai and Lin 2010), suggesting a relatively narrow therapeutic window for partial agonists at the glycine sites (Hashimoto et al. 2013).

1-Aminocyclopropanecarboxylic acid (ACPC) is a highaffinity partial agonist at the strychnine-insensitive glycine sites (Marvizon et al. 1989) that exhibits anticonvulsant (Witkin and Tortella 1991), neuroprotective (Von Lubitz et al. 1992; Fossom et al. 1995), anxiolytic (Trullas et al. 1989), anti-addictive (Kolesnikov et al. 1994) and antidepressant-like (Trullas and Skolnick 1990; Trullas et al. 1991; Papp and Moryl 1996) effects in rats and mice. This broad range of pharmacological effects is reminiscent of NMDA antagonists.

However, in contrast to NMDA receptor antagonists acting at other loci and the full antagonist of the glycine site 7-chlorokynurenic acid that impair spatial learning (Bannerman et al. 1997; Carli et al. 2001), the functional NMDA/glycine receptor antagonist ACPC does not impair memory or learning processes in a step-through avoidance (Faiman et al. 1994). Conversely, preclinical studies demonstrated that ACPC facilitates spatial learning in senescent rats (Popik and Rygielska 1999) and in mice tested in a single-trial inhibitory avoidance learning both in naive animals and following administration of a variety of amnestic agents (Viu et al. 2000). These properties make ACPC a particularly interesting molecule to investigate both in tests addressing cognitive deficits observed in schizophrenia (NMDAR antagonist-disturbed conditions, prefrontal cognitive flexibility) as well as in procedures used to detect potential antipsychotic activity (PCP-induced hyperactivity, CAR, PPI). Here, ACPC was also tested in the five-choice serial reaction time task (5-CSRTT), a procedure that permits the simultaneous examination of multiple aspects of attentional performance (Bari et al. 2008) including the accuracy of attentional processes and impulsivity. While NMDAR antagonists (e.g., MK-801, PCP) have been demonstrated to disrupt attentional performance and/or increase impulsivity (reviewed in (Amitai and Markou 2010)), the effects of glycinergic compounds have not been widely assessed in this task.

\section{Materials and methods}

\section{Animals}

Male Sprague-Dawley rats (Charles River, Germany) weighing $250-280 \mathrm{~g}$ on arrival were used in this study. Animals were initially group-housed (five rats/cage) in a temperature- $\left(21 \pm 1{ }^{\circ} \mathrm{C}\right)$ and humidity- $(40-50 \%)$ controlled colony room under a 12/12-h light/dark cycle (lights on at 06:00 h). Rats were allowed to acclimatize for at least 7 days before the start of the experimental procedures. In the ASST, rats were individually housed with mild food restriction (15 $\mathrm{g}$ 
of food pellets per day) and ad libitum access to water for 1 week prior to testing. For the 5-CSRTT, rats were grouphoused (four rats/cage) with mild food restriction ( $15 \mathrm{~g}$ of food pellets per day). Behavioral testing was performed during the light phase of the light/dark cycle. The experiments were conducted in accordance with the NIH Guide for the Care and Use of Laboratory Animals and were approved by the Ethics Committee for Animal Experiments, Institute of Pharmacology. All rats were used only once, and each experiment was carried out on a separate cohort of animals.

\section{Novel object recognition test (NOR)}

The protocol described earlier (Nikiforuk et al. 2013) was adapted from the original work of Ennaceur and Delacour (1988). At least $1 \mathrm{~h}$ before the start of the experiment, the rats were transferred to the experimental room for acclimation. Animals were tested in a dimly lit (25 lx) open-field apparatus made of a dull gray plastic $(66 \times 56 \times 30 \mathrm{~cm})$. After each measurement, the floor was cleaned and dried. The procedure consisted of a 5-min habituation to the arena without any objects, $24 \mathrm{~h}$ before the test. The testing comprised two trials separated by an inter-trial interval (ITI). To test the memory improvement in naive animals, an ITI of $24 \mathrm{~h}$ was chosen. To test the memory improvement in either PCP- or KETdisturbed conditions, a 1-h ITI was chosen.

During the first (familiarization, T1) test period, two identical objects (A1 and A2) were presented in the opposite corners of the arena, approximately $10 \mathrm{~cm}$ from the walls. Following T1, the objects were cleaned with water containing a dishwashing agent and dried. In the second trial (recognition, T2) one of the objects was replaced by a novel one $(\mathrm{A}=$ familiar and $\mathrm{B}=$ novel). Both trials lasted for $3 \mathrm{~min}$. After T1, animals were returned to their home cages. The objects used were a $250-\mathrm{ml}$ glass beaker (diameter of $8 \mathrm{~cm}$, height of $14 \mathrm{~cm})$ filled with gravel $(350 \mathrm{~g})$ and a $250-\mathrm{ml}$ plastic bottle $(6 \times 6 \times 13 \mathrm{~cm})$ filled with sand $(450 \mathrm{~g})$. The location of the novel object in T2 was randomly assigned for each rat. Exploration of an object was defined by rats looking, licking, sniffing, or touching the object, but not leaning against, standing, or sitting on the object. The exploration time of the objects was measured using the Any-maze ${ }^{\circledR}$ tracking system (Stoelting Co., IL, USA). Based on the exploration time $(E)$ of the two objects, a discrimination index was calculated in accordance with the formula discrimination index $(\mathrm{DI})=\left(E_{\mathrm{B}}-E_{\mathrm{A}}\right) /\left(E_{\mathrm{A}}+E_{\mathrm{B}}\right)$, where $E_{\mathrm{A}}$ is defined as the time spent exploring the familiar object and $E_{\mathrm{B}}$ is the time spent exploring the novel object, respectively.

Attentional set-shifting test (ASST)

Testing was conducted in a modified wire rat housing cage $(42 \times 32 \times 22 \mathrm{~cm})$ with a white plywood wall dividing half of the length of the cage into two sections. During testing, one ceramic digging pot (diameter of $10 \mathrm{~cm}$, height of $2 \mathrm{~cm}$ ) was placed in each section. Each pot was defined by a pair of cues along with two stimulus dimensions (the digging media and odors, as described in details by Nikiforuk et al. (2010)). To mark each pot with a distinct odor, $5 \mu$ of a flavoring essence (Dr. Oetker ${ }^{\circledR}$, Poland) was applied to a small piece of blotting paper fixed to the external rim of the pot immediately prior to use. A different pot was used for each combination of digging medium and odor; only one odor was ever applied to a given pot. The bait (one-third of a Honey Nut Cheerio, Nestle ${ }^{\circledR}$ ) was placed at the bottom of the "positive" pot and buried in the digging medium.

The procedure was adapted from Birrell and Brown (2000) and entailed three testing days for each rat, as described in details elsewhere (Nikiforuk et al. 2011). In simple discrimination (SD) involving only one stimulus dimension, the pots differed along one of the two dimensions (i.e., a digging medium). For compound discrimination (CD), a second, irrelevant, dimension (i.e., an odor) was introduced, but the correct and incorrect exemplars of the relevant dimension remained constant. For the reversal of this discrimination (Rev 1), the exemplars and relevant dimension were unchanged, but the previously correct exemplar was now incorrect and vice versa. The intra-dimensional (ID) shift was then presented, comprising new exemplars of both the relevant and irrelevant dimensions with the relevant dimension remaining the same as previously. The ID discrimination was then reversed (Rev 2) so that the formerly positive exemplar became the negative one. For the most essential, extra-dimensional (ED) shift, a new pair of exemplars was again introduced, but this time, a relevant dimension was also changed. Finally, the last phase was the reversal (Rev 3 ) of the ED discrimination problem. The exemplars were always presented in pairs and varied so that only one animal within each treatment group received the same combination. The following pairs of exemplars were used: pair 1: odor: lemon vs. almond, medium: cotton wool vs. crumpled tissue; pair 2: odor: spicy vs. vanilla, medium: metallic filler vs. shredded paper; and pair 3: odor: rum vs. cream, medium: clay pellets vs. silk. Our previous study demonstrated that there were no differences in the performance of rats shifted from odor to medium and from medium to odor (Nikiforuk et al. 2010). Therefore, in an attempt to simplify the experimental design, the order of discrimination was always the same (i.e., from digging medium to odor). The assignment of each exemplar in a pair as being positive or negative at a given phase and the left-right positioning of the pots in the test apparatus on each trial were randomized.

Spontaneous and PCP-induced hyperactivity

Spontaneous and PCP-induced locomotor activity was measured automatically in Opto-Varimex-4 Auto-Tracks 
(Columbus Instruments, OH, USA) located in soundattenuated and ventilated boxes. The Auto-Track System sensed the motion with a grid of infrared photocells ( 16 beams per axis) surrounding the arena.

\section{Conditioned avoidance response (CAR)}

The training and the testing were performed in four shuttle boxes (Med Associates, Inc., USA). Each box $(44 \times 21 \times$ $18 \mathrm{~cm}$ ) was housed in ventilated, sound-isolated cubicles and was divided in two equal-sized compartments by guillotine doors. The rats were allowed to move freely from one compartment to another at any time. The position of the animal was tracked by eight photocells in each of the boxes. A cue light was situated on the wall opposing the compartment entry.

The sessions were started by presenting the conditioned stimulus (CS; the light) for $10 \mathrm{~s}$, followed by an unconditioned stimulus (UCS; continuous foot shock of $0.37 \mathrm{~mA}$ ) for the maximum duration of $10 \mathrm{~s}$. The procedure was repeated with 20 trials daily with an intra-trial interval of $20-40$ s. If a rat moved from one compartment to another within $10 \mathrm{~s}$ of CS presentation, it avoided the foot shock, and this shuttle response was recorded as avoidance. If the rat remained in the compartment for more than $10 \mathrm{~s}$ and made a crossing upon receiving the foot shock, this response was recorded as an escape. If the rats did not respond either during the $10 \mathrm{~s}$ of CS or by $10 \mathrm{~s}$ of UCS, the trial was terminated and escape failure was recorded. It is known that compounds displaying antipsychotic activity selectively inhibit avoidance response without affecting escapes and failures (Wadenberg and Hicks 1999).

About 12-15 training sessions, lasting for 2-3 weeks, were needed to train the animals to the stable avoidance level of above $80 \%$ in two consecutive days. The rats fulfilling these criteria $(\sim 60 \%)$ were given different doses of ACPC or clozapine as a positive control. Due to the nature of the test, allowing for repeated testing (Wadenberg and Hicks 1999), animals were drug tested up to three times with a 7-day drugfree period between tests according to a randomized design (Wadenberg et al. 1997).

Prepulse inhibition of the acoustic startle response (PPI)

The PPI procedure was adopted from a published protocol (Auclair et al. 2006). Rats were subjected to two pretest sessions: an afternoon session on the day before testing and a morning session on the test day (Fijal et al. 2014). We used a startle apparatus (Med Associates, Inc., USA) consisting of acrylic animal holders with a grid floor made of stainless bars, mounted onto a startle platform placed in a ventilated, soundattenuated chambers (Nikiforuk et al. 2013). Acoustic stimuli were generated by two speakers: a background-noise speaker and a stimulus speaker, placed at the back of the chamber,
$7 \mathrm{~cm}$ from an animal holder. Startle responses were detected and transduced by the load cell, then digitized and stored by Startle Reflex Software (Med Associates, version 5).

Each session started with a 5-min acclimatization period. A 62-dB background white noise was continuously presented once animals were placed in the test chambers. The following types of acoustic stimuli were used in the test protocol: pulse alone [intensity, $120 \mathrm{~dB}$; duration, $40 \mathrm{~ms}$, (P)], pulse preceded by an acoustic prepulse of intensities 70,73 , and $76 \mathrm{~dB}$ [duration, $20 \mathrm{~ms}$, (PP)], applied $100 \mathrm{~ms}$ before the pulse (P), prepulse alone [intensities, 70, 73, and $76 \mathrm{~dB}$; duration, $20 \mathrm{~ms}$ ], and a null period. The session consisted of three blocks. During the first block, the animals were exposed to ten pulse-alone trials. During the second block, the following trials were presented in random order: pulse alone, pulse preceded by each prepulse, along with one repetition of each prepulse alone, and four null trials. The inter-trial interval was $20 \mathrm{~s}$. The third block consisted of ten pulse-alone trials. Earlier experiments in this laboratory demonstrated that four presentations of each trial type - as compared to the more common 10 presentations protocolconsistently revealed the antipsychotic-like activity of clozapine $(5 \mathrm{mg} / \mathrm{kg}$ IP, given $25 \mathrm{~min}$ before the test (Fijal et al. 2014)). Therefore, in the present experiments, we used four repetitions of each trial type.

\section{Five-choice serial reaction time task (5-CSRTT)}

Two separate cohorts were trained in the 5-CSRTT. Eight 5CSRTT operant chambers (Med Associates, Inc., USA), measuring $56 \times 56 \times 40.5 \mathrm{~cm}$, were housed in sound-attenuated, ventilated cubicles. In each chamber, an array of five square nose-poke holes $(2.5 \times 2.5 \times 2.5 \mathrm{~cm})$ was arranged on a curved panel and raised $2.5 \mathrm{~cm}$ from the grid floor. Each hole was equipped with an infrared detector and a yellow stimulus light at its rear. The food magazine, equipped with photocell beams and light, was located on the opposite wall. Food pellets (45 mg, Bio-Serv, USA) were delivered via a dispenser connected to the food magazine. A house light was located $17 \mathrm{~cm}$ above the top edge of the food magazine. Online control of the apparatus and data collection was performed using MED-PC (Med Associates, Inc., USA).

In the initial training phase of magazine training, rats had to learn that food pellets were available in the magazine. On the first day, rats were habituated to the operant chambers for $15 \mathrm{~min}$. During this habituation session, the food magazine was filled with several pellets. Next, rats were given magazine training sessions, in which every head entry into a food magazine resulted in a pellet delivery. Once all rats ate 100 food pellets within a session (which usually took one-two sessions), the training proceeded to the next stage.

In the next phase of pretraining, rats had to learn to associate a nose-poke response into an illuminated hole with a pellet delivery. All of the five holes were illuminated, and a 
response in any aperture was rewarded by a food pellet. This procedure was continued daily until rats obtained 100 pellets within a session.

In the 5-CSRTT training and testing phase, each session began with the illumination of the house light and delivery of a food pellet. A nose poke into the magazine tray initiated the first trial, which consisted of an inter-trial interval (ITI) followed by the random illumination of one of the five holes for a fixed interval (stimulus duration, $\mathrm{Sd}$ ). If a nose poke was registered in the illuminated hole before the end of the limited hold (Lho, i.e., a fixed interval after Sd), a pellet was delivered and a correct trial was registered. An incorrect response or a failure to respond within the required period (omission) resulted in a time-out (TO) period, in which the house light was extinguished. Responding to any of the five holes during the ITI (premature response) also resulted in a TO. For the first session of training, the stimulus duration and limited hold periods were both set at $60 \mathrm{~s}$ and the ITI and TO were $2 \mathrm{~s}$. These variables were gradually altered during training, so the final test parameters were as follows: $\mathrm{Sd}=1 \mathrm{~s}, \mathrm{Lho}=5 \mathrm{~s}$, ITI $=$ $5 \mathrm{~s}, \mathrm{TO}=5 \mathrm{~s}$. Rats had been trained until they reached the criteria of accuracy $>70 \%$, omissions $<30 \%$, and stable baseline performance over five consecutive sessions (that took approximately 60 training sessions). Each session lasted for 30 min or until 100 trials had been completed. During testing sessions, all rats completed 100 trials within $30 \mathrm{~min}$.

\section{Drugs}

1-Aminocyclopropanecarboxylic acid (ACPC) kindly donated by Dr. M-L Maccecchini, phencyclidine hydrochloride (Sigma-Aldrich, USA), ketamine (aqueous solution (115.34 mg/ml; Biowet Pulawy, Poland)), and MK-801 maleate (Abcam Biochemicals, Cambridge, UK) were dissolved in distilled water. Clozapine (Abcam Biochemicals, Cambridge, UK) was dissolved in $0.1 \mathrm{~N} \mathrm{HCl}$ supplemented with distilled water to the appropriate volume (final $\mathrm{pH}=5.0-6.0$ ). All compounds were administrated in a volume of $1 \mathrm{ml} / \mathrm{kg}$, except ACPC at $400 \mathrm{mg} / \mathrm{kg}$ which was administered in a volume of $2 \mathrm{ml} / \mathrm{kg}$ due to solubility limitations.

\section{Drug administration}

The doses, routes, and times of administration of compounds that maximized the chance to observe a given effect were selected based on previously published data (Popik and Rygielska 1999; Nikiforuk et al. 2010, 2011, 2013; Fijal et al. 2014).

\section{Novel object recognition test (NOR)}

In the naive animals, ACPC was administered IP, $30 \mathrm{~min}$ before familiarization phase (T1). Separate groups of animals tested in the NMDAR antagonist-disturbed conditions, received ketamine $(20 \mathrm{mg} / \mathrm{kg}$, IP) and phencyclidine $(5 \mathrm{mg} / \mathrm{kg}$, IP) $45 \mathrm{~min}$ before $\mathrm{T} 1$, and either ACPC or clozapine was administered 30 min before ketamine, PCP, or vehicle.

\section{Attentional set-shifting test (ASST)}

ACPC (200-400 mg/kg IP) was administered $30 \mathrm{~min}$ before the test.

\section{Spontaneous and PCP-induced hyperactivity}

Separate groups of animals were administered ACPC, clozapine, or their vehicles IP, $30 \mathrm{~min}$ before being placed individually into the auto-tracks for $30 \mathrm{~min}$ of spontaneous locomotor activity measurement. Thereafter, the same rats were removed from the boxes and injected with PCP at a dose of $5 \mathrm{mg} / \mathrm{kg}$ (SC), and then, the PCP-induced locomotor activity was measured for the following 15-45 $\mathrm{min}$.

\section{Conditioned avoidance response (CAR)}

ACPC (200-400 mg/kg IP) and clozapine (1-6 mg/kg, IP) were administered 30 and 60 min before the test, respectively.

\section{Prepulse inhibition of the acoustic startle response (PPI)}

Naive rats received ACPC (100-400 mg/kg IP) 15 min before the test. In ketamine-disturbed conditions, ACPC (200$400 \mathrm{mg} / \mathrm{kg}$, IP) and ketamine (10 mg/kg SC) were administered 15 and $5 \mathrm{~min}$, respectively, before the test.

\section{Five-choice serial reaction time task (5-CSRTT)}

ACPC (200-400 mg/kg, IP) and MK-801 (12.5-50 $\mu \mathrm{g} / \mathrm{kg}$, SC) were administered 30 and $10 \mathrm{~min}$ before the test, respectively.

\section{Data analysis}

Data were analyzed using IBM/SPSS 21 for Windows. The alpha value was set at $P<0.05$. The homogeneity of variance was measured with Levene's test.

\section{Novel object recognition test (NOR)}

Discrimination index (DI) data were analyzed using one-way ANOVAs with drug dose as between-subject factor. Sidak's test was used as a post hoc test (Howell 1997). 


\section{Attentional set-shifting test (ASST)}

The number of trials required to achieve the criterion of six consecutive correct responses was recorded for each rat and for each discrimination phase. The data were assessed by twoway ANOVA with ACPC dose as a between-subject factor and discrimination phase ( $\mathrm{SD}, \mathrm{CD}, \mathrm{Rev} 1, \mathrm{ID}$, etc.) as a within-subject factor. Sidak's test was used as a post hoc test.

\section{Spontaneous and PCP-induced hyperactivity}

The activity data collected every $5 \mathrm{~min}$ are presented as area under curve of the total distance traveled, in centimeter. The measurement of the first 30 min indicates ACPC- or clozapineinduced effects on spontaneous locomotor activity. The second period (measured in the same animals 15-45 min following PCP administration) indicates drug-induced alteration of PCPinduced hyperactivity (Gleason and Shannon 1997). Separate
ANOVAs followed by Dunnett's multiple comparison tests were used to assess the effects of compounds on activity.

\section{Conditioned avoidance response (CAR)}

Separate one-way ANOVAs, followed by Tukey's post hoc tests, were used to assess the effects of ACPC and clozapine on the percentage of conditioned avoidance responding and of escape failures.

\section{Prepulse inhibition of the acoustic startle response (PPI)}

The mean response amplitude for pulse-alone $[\mathrm{P}]$ and prepulse + pulse [PP] trials was computed for each rat, and PPI was determined according to the formula: $\mathrm{PPI}(\%)=[(\mathrm{P}-\mathrm{PP}) / \mathrm{P}] \times$ 100. Percentage PPI data were analyzed using two-way ANOVAs with the between-subject factors of drug treatment and prepulse intensity as a within-subject factor followed by
Fig. 1 (a) ACPC improves object recognition memory in the novel object recognition (NOR) test at a long $(24 \mathrm{~h})$ inter-trial interval (ITI) in naive animals (**P<0.01, *** $P<0.001$ vs. vehicle; $N=10$ rats per dose). (b) At a short (1 h) ITI, ketamine $(20 \mathrm{mg} / \mathrm{kg}$ ) disturbs object recognition memory $(* * * P<0.001$ vs. vehicle) and $400 \mathrm{mg} / \mathrm{kg}$ of ACPC prevents ketamine-induced disturbance

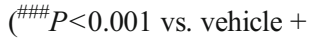
ketamine); $N=9-10$ rats per dose. (c) At a short (1 h) ITI, PCP $(5 \mathrm{mg} / \mathrm{kg}$ ) disturbs object recognition memory $(* * * P<0.001$ vs. vehicle) and $400 \mathrm{mg} / \mathrm{kg}$, but not $200 \mathrm{mg} / \mathrm{kg}$ of ACPC, prevents PCP-induced disturbance (\#\#P<0.01 vs. vehicle $+\mathrm{PCP}) ; N=8-10$ rats per dose. (d) A similar procognitive effect of $1 \mathrm{mg} / \mathrm{kg}$ of clozapine, which at a short (1 h) ITI, prevents from PCP-induced disturbance $(\# \# \#<0.001$ vs. vehicle + PCP); $N=9-11$ rats per dose. Values represent the mean $( \pm$ SEM) of discrimination index ITI $=24 \mathrm{~h}$
undisturbed conditions

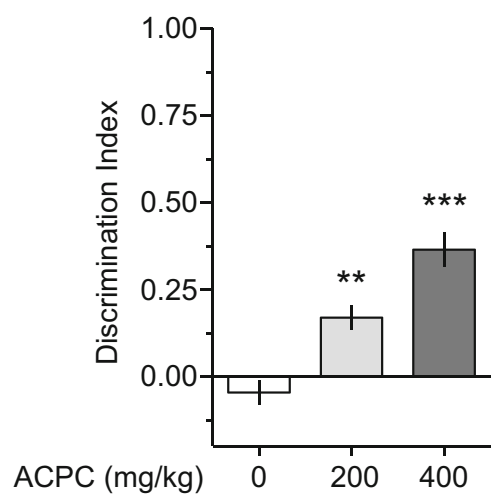

C $\mathrm{ITI}=1 \mathrm{~h}$
PCP-disturbed

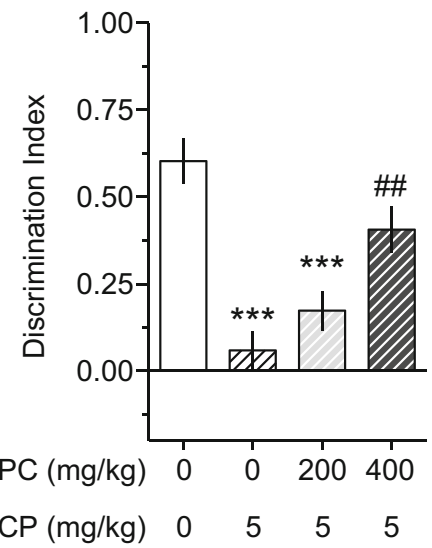

b

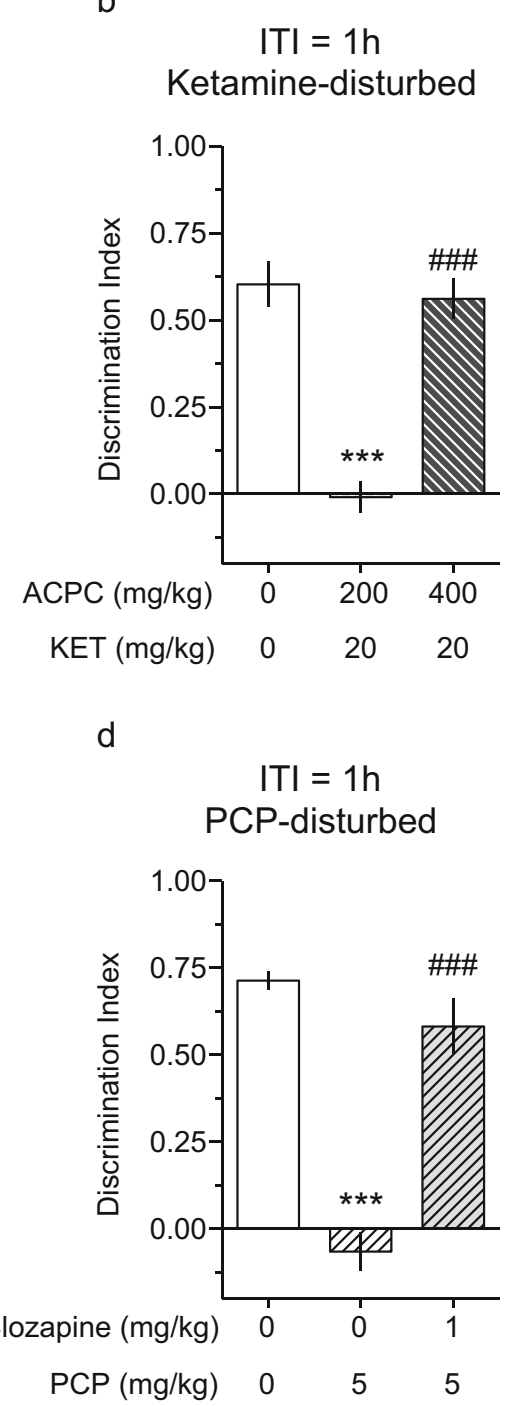


Fisher's protected LSD. Pulse amplitude values, (calculated as the average response to all of the pulse-alone trials) were subjected to one-way ANOVAs.

\section{Five-choice serial reaction time task (5-CSRTT)}

The following parameters were recorded in each session: percent of accuracy (number of correct responses divided by the sum of correct and incorrect responses $\times 100$ ), number of premature responses (total number of responses performed during the ITIs), omissions (total number of trials omitted during a 100-trial session), correct response latency (time from the stimulus onset to a correct response), reward latency (time from a correct response to the retrieval of food from the magazine), as well as perseverant responses (total number of responses emitted after a correct response has been made). The data regarding the accuracy (the main measure of performance) and the number of premature responses (the main measure of impulsivity) are presented on Fig. 6; the other data are presented in Table 3. Separate one-way ANOVAs, followed by Tukey's post hoc tests, were used to assess the effects of ACPC and MK-801 on the outcome of 5CSRTT.

\section{Results}

Novel object recognition test (NOR)

As shown in Fig. 1a, ACPC dose-dependently improved object recognition memory in naive rats at the long ( $24 \mathrm{~h})$ inter-trial interval: $F(2.27)=25.35, P<0.001$. At $1 \mathrm{~h}$ inter-trial interval, ketamine $(20 \mathrm{mg} / \mathrm{kg})$ produced an impairment of object recognition memory, which was alleviated by
Table 1 The effects of treatments on the exploration of objects A1 and $\mathrm{A} 2$ used during test 1 in the novel object recognition test

\begin{tabular}{|c|c|c|}
\hline Treatment $(N)$ & Object A1 exploration $(s)$ & Object A2 exploration $(s)$ \\
\hline \multicolumn{3}{|c|}{$\mathrm{ITI}=24 \mathrm{~h}$, undisturbed conditions } \\
\hline Vehicle (10) & $12.66 \pm 1.07$ & $11.70 \pm 1.13$ \\
\hline ACPC 200 mg/kg (10) & $10.84 \pm 0.67$ & $11.25 \pm 1.20$ \\
\hline ACPC 400 mg/kg (10) & $11.31 \pm 1.38$ & $12.15 \pm 1.08$ \\
\hline \multirow[t]{3}{*}{ Statistics of two-way mixed-design ANOVA } & \multicolumn{2}{|c|}{ Treatment: $F(2.27)=0.33$; NS } \\
\hline & \multicolumn{2}{|l|}{ Object: $F(1.27)=0.02 ; \mathrm{NS}$} \\
\hline & \multicolumn{2}{|c|}{ Treatment $\times$ object: $F(2.27)=0.88 ; \mathrm{NS}$} \\
\hline \multicolumn{3}{|c|}{$\mathrm{ITI}=1 \mathrm{~h}$, ketamine disturbed } \\
\hline Vehicle (10) & $8.37 \pm 0.78$ & $9.43 \pm 0.62$ \\
\hline $\mathrm{VEH}+\mathrm{KET} 20 \mathrm{mg} / \mathrm{kg}(9)$ & $10.38 \pm 0.95$ & $12.09 \pm 1.20$ \\
\hline ACPC 400+KET 20 mg/kg (10) & $9.15 \pm 0.68$ & $10.58 \pm 1.06$ \\
\hline \multirow[t]{3}{*}{ Statistics of two-way mixed-design ANOVA } & \multicolumn{2}{|c|}{ Treatment: $F(2.26)=2.50$; NS } \\
\hline & \multicolumn{2}{|c|}{ Object: $F(1.26)=5.44 ; P<0.05$} \\
\hline & \multicolumn{2}{|c|}{ Treatment $\times$ object: $F(2.26)=0.90 ; \mathrm{NS}$} \\
\hline \multicolumn{3}{|c|}{$\mathrm{ITI}=1 \mathrm{~h}, \mathrm{PCP}$ disturbed } \\
\hline Vehicle (8) & $10.83 \pm 0.73$ & $9.75 \pm 0.59$ \\
\hline VEH+PCP 5 mg/kg (9) & $9.23 \pm 1.13$ & $9.61 \pm 0.82$ \\
\hline ACPC $200+$ PCP 5 mg/kg (10) & $8.85 \pm 1.27$ & $8.73 \pm 1.09$ \\
\hline ACPC $400+$ PCP 5 mg/kg (10) & $9.89 \pm 1.46$ & $10.01 \pm 0.94$ \\
\hline \multirow[t]{3}{*}{ Statistics of two-way mixed-design ANOVA } & \multicolumn{2}{|c|}{ Treatment: $F(3.33)=0.50$; NS } \\
\hline & \multicolumn{2}{|l|}{ Object: $F(1.33)=0.08$; NS } \\
\hline & \multicolumn{2}{|c|}{ Treatment $\times$ object: $F(3.33)=0.26$; NS } \\
\hline \multicolumn{3}{|c|}{$\mathrm{ITI}=1 \mathrm{~h}, \mathrm{PCP}$ disturbed } \\
\hline Vehicle (9) & $8.76 \pm 1.08$ & $8.54 \pm 0.52$ \\
\hline $\mathrm{VEH}+\mathrm{PCP} 5$ mg/kg (9) & $7.31 \pm 1.00$ & $7.60 \pm 1.13$ \\
\hline Clozapine 1+PCP 5 mg/kg (11) & $6.95 \pm 1.18$ & $9.08 \pm 0.86$ \\
\hline \multirow[t]{3}{*}{ Statistics of two-way mixed-design ANOVA } & \multicolumn{2}{|c|}{ Treatment: $F(2.26)=0.53$; NS } \\
\hline & \multicolumn{2}{|c|}{ Object: $F(1.26)=1.03 ; \mathrm{NS}$} \\
\hline & \multicolumn{2}{|c|}{ Treatment $\times$ object: $F(2.26)=1.05 ; \mathrm{NS}$} \\
\hline
\end{tabular}


$400 \mathrm{mg} / \mathrm{kg}$ of ACPC: $F(2.26)=41.81, P<0.001$ (Fig. 1b). At 200 and $400 \mathrm{mg} / \mathrm{kg}$, ACPC also prevented PCP-induced impairment of object recognition memory: $F(3.33)=14.82$, $P<0.001$ (Fig. 1c). The "positive" control, clozapine $(1 \mathrm{mg} / \mathrm{kg})$, similarly prevented an impairment of object recognition memory in PCP-induced disturbed conditions: $F(2.26)=42.76, P<0.001$ (Fig. 1d). Table 1 shows that the compounds used did not affect the exploration of objects during familiarization phase (T1).

\section{Attentional set-shifting test (ASST)}

Figure 2 shows that the animals required more trials to the criterion at the ED phase than at the ID phase, suggesting that the presently used experimental conditions allowed for building an attentional set. ACPC reduced the number of trials to criterion at the ED phase (Fig. 2) at the dose of 400 but not $200 \mathrm{mg} / \mathrm{kg}$, suggesting an improvement of cognitive flexibility. Two-way ANOVA demonstrated a significant interaction between the dose and the phase of discrimination: $F(12.90)=$ $3.85, P<0.001$.

\section{Spontaneous and PCP-induced hyperactivity}

Figure 3 a demonstrates that clozapine inhibited spontaneous activity at the dose of $3 \mathrm{mg} / \mathrm{kg}(F(3.30)=4.94, P<0.005)$. In addition, clozapine attenuated $\mathrm{PCP}$-induced hyperactivity already at the dose of $1 \mathrm{mg} / \mathrm{kg}(F(3.30)=4.23, P<0.025$, Fig. 3b), a characteristic for antipsychotic-like activity. In contrast, ACPC affected neither spontaneous activity $(F(3.39)=0.1$, Fig. 3c) nor PCP-induced hyperactivity $(F(3.39)<1$, Fig. 3d).

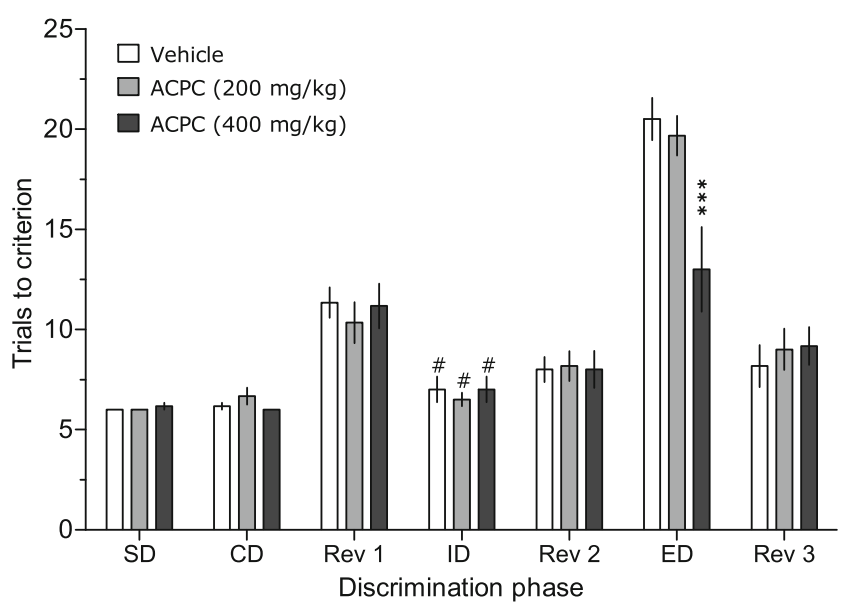

Fig. 2 ACPC enhances cognitive flexibility in the attentional set-shifting test (ASST) in otherwise untreated rats at the dose of 400 but not $200 \mathrm{mg} / \mathrm{kg}$. $* * * P<0.001$ vs. vehicle at the ED phase, $\# P<0.01$ vs. respective ED phase, $N=6$ rats per dose. Values represent the mean $( \pm$ SEM) number of trials to a given criterion
Conditioned avoidance response (CAR)

ACPC did not affect conditioned avoidance responding: $F(2.16)=0.49$, NS. In contrast, clozapine ( 3 and $6 \mathrm{mg} / \mathrm{kg}$ ) reduced avoidance responses, indicative of antipsychotic-like efficacy, $F(3.42)=26.85, P<0.001$. Clozapine did not affect escape failures $(F(3.42)=1.10, \mathrm{NS})$ indicating that at these doses, it does not produce sedation or motor side effects (Fig. 4).

Prepulse inhibition of the acoustic startle response (PPI)

ACPC did not affect PPI in naive animals (Fig. 5a, $F(4.33)=$ 2.12 , NS). There was no interaction between dose and prepulse intensity: $F(8.66)=1.80$, NS, but, as expected, a significant effect of prepulse intensity: $F(2.66)=17.90$, $P<0.001$. One-way ANOVA showed significant differences in the pulse amplitude: $F(4.33)=2.80, P<0.05$, and ACPC at only the single dose of $200 \mathrm{mg} / \mathrm{kg}$ increased startle amplitude as compared with vehicle (Table 2).

Figure $5 \mathrm{~b}$ shows that ACPC did not affect PPI under ketamine-disturbed conditions. Two-way ANOVA showed no significant treatment effect $(F(3.24)=1.43$, NS and prepulse intensity: $F(2.48)=0.25)$. The significant interaction between treatment and prepulse intensity: $F(6.48)=3.57$, $P<0.01$ allowed for performing a post hoc test, which revealed that at an intensity of $73 \mathrm{~dB}$, both vehicle + ketamine as well as $400 \mathrm{mg} / \mathrm{kg}$ of ACPC + ketamine-disrupted PPI, suggesting a lack of antipsychotic-like activity of ACPC. Oneway ANOVA showed no significant effects of treatment on pulse amplitude: $F(3.24)=0.6$, NS (Table 2).

\section{Five-choice serial reaction time task (5-CSRTT)}

ACPC affected neither the percentage of accuracy: $F(2.29)=$ 0.52 , Fig. $6 \mathrm{a}$ nor the number of premature responses: $F(2.29)=0.60$, Fig. 6c. Table 3 shows that ACPC did not affect omissions, correct response latency, reward latency, or perseverant responses. While MK-801 at relatively low (25$50 \mu \mathrm{g} / \mathrm{kg}$ ) doses did not affect accuracy: $F(3.27)=1.03$, Fig. 6b, as expected (Higgins et al. 2003) it dosedependently increased the number of premature responses, a measure of impulsivity: $F(3.27)=5.48, P<0.01$, Fig. $6 \mathrm{~d}$. Consistent with these effects, treatment with MK-801 reduced correct response latency and reward latency, but did not affect the number of omissions and perseverant responses (Table 3).

\section{Discussion}

The present study demonstrates that ACPC, a partial agonist at the strychnine-insensitive glycine receptors (Marvizon et al. 1989), facilitates object recognition learning in the novel 
Fig. 3 In contrast to clozapine, which inhibited PCP-induced hyperactivity (b) at a dose lower than that producing sedation (a), ACPC affected neither spontaneous activity (c) nor PCPinduced hyperactivity (d). Values represent the mean $( \pm \mathrm{SEM})$ distance traveled, expressed as the area under the curve (AUC), in centimeter. Spontaneous activity was measured for the first $30 \mathrm{~min}$ following drug administration. PCP-induced hyperactivity was also measured for $30 \mathrm{~min}$, starting 15 min after PCP administration. $* * P<0.01$ vs. vehicle control, $\# P<0.05$ vs. PCP. $N=8-9$ rats per dose (clozapine study) and 8-16 rats per dose (ACPC study) a

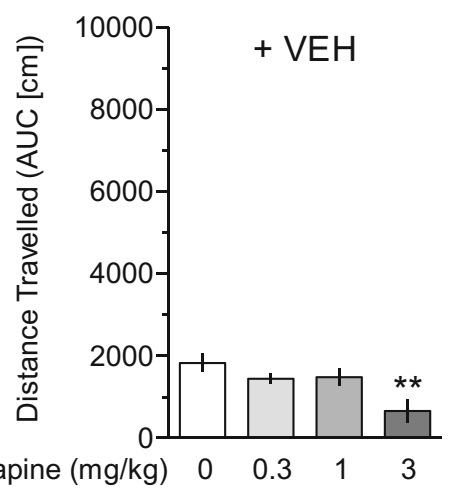

C

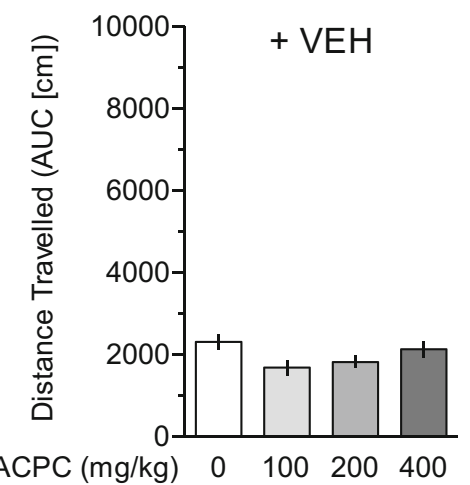

b

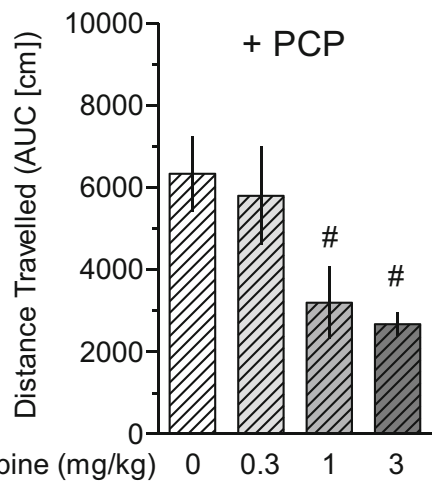

d

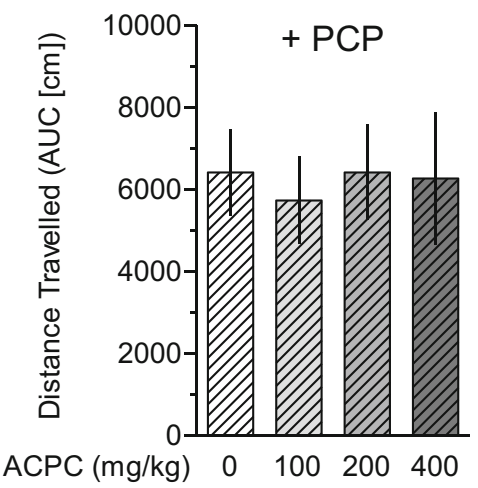

object recognition test in both the presence and absence of NMDAR antagonists, and enhances cognitive flexibility in the attentional set-shifting task. However, ACPC produced no measurable effects in PCP-induced hyperactivity, conditioned avoidance response, and prepulse inhibition tests, suggesting a lack of antipsychotic-like activity. Like MK-801, ACPC did

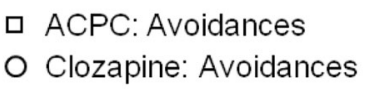

$\triangle$ ACPC: Failures

O Clozapine: Avoidances

$\diamond$ Clozapine: Failures

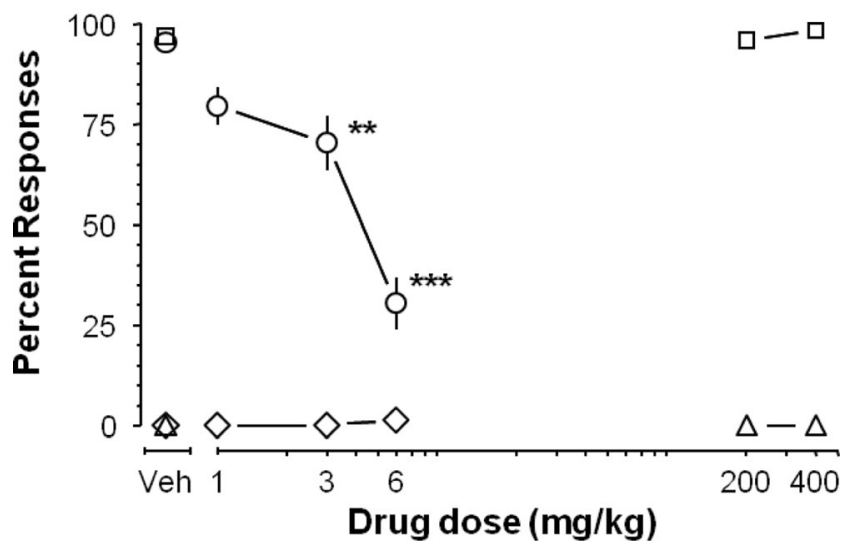

Fig. 4 In the conditioned avoidance response (CAR) test, ACPC affected neither avoidance responses nor escape failures. In contrast, clozapine ( 3 and 6 , but not $1 \mathrm{mg} / \mathrm{kg}$ ) selectively inhibited avoidance responses without affecting escape failures, indicating an antipsychotic-like effect. Values represent the mean $( \pm \mathrm{SEM})$ percentage of avoidance responses and escape failures. $* * P<0.01$, $* * * P<0.001$ vs. vehicle control. $N=5-8$ rats per dose (ACPC study) and 10-11 rats per dose (clozapine study) not affect accuracy in the five-choice serial reaction time task, but in contrast to very low doses of MK-801 (Higgins et al. 2003), no increase in impulsivity was observed. The latter findings strongly suggest prominent differences in the pharmacological profile of ACPC compared to NMDA channel blockers. Thus, despite the functional antagonist properties of ACPC documented in multiple studies, it did not disturb object recognition learning like PCP and ketamine (Fig. 1), did not disturb prepulse response like ketamine (Fig. 5), and did not affect impulsivity like MK-801 (Fig. 6).

\section{Cognition}

While an impairment of cognitive flexibility due to NMDAR blockade has been broadly reported (Stefani et al. 2003; Egerton et al. 2005; Nikiforuk et al. 2010), much less is known about the effects of agents enhancing NMDAR-mediated responses on ASST performance.

Preclinical studies with glycine site ligands demonstrated procognitive actions of the glycine agonist D-serine (Duffy et al. 2008) and the partial agonist ACPC (Popik and Rygielska 1999) in the Morris water maze, as well as the partial agonist Dcycloserine in the radial maze (Pussinen and Sirvio 1999). In addition, the GlyT1 inhibitor SSR-504734 facilitated working memory in a continuous delayed alternation task in mice (Singer et al. 2009). Perhaps more relevant to the present work are the findings of Shimazaki et al. (2010) demonstrating that the GlyT1 
Fig. 5 In the prepulse inhibition of the acoustic startle response (PPI) test, ACPC affected prepulse inhibition response neither in (a) naive animals, suggesting the lack of psychotomimetic effects, nor in (b) ketamine-induced PPI disturbed conditions, suggesting the lack of antipsychotic-like effects. Values represent the mean $( \pm$ SEM) percentage of prepulse inhibition. $* P<0.05$, vs. vehicle control at a given prepulse intensity expressed in decibel. $N=4-15$ rats per dose (naive animals) and 4-11 rats per dose (ketamine-disturbed conditions)
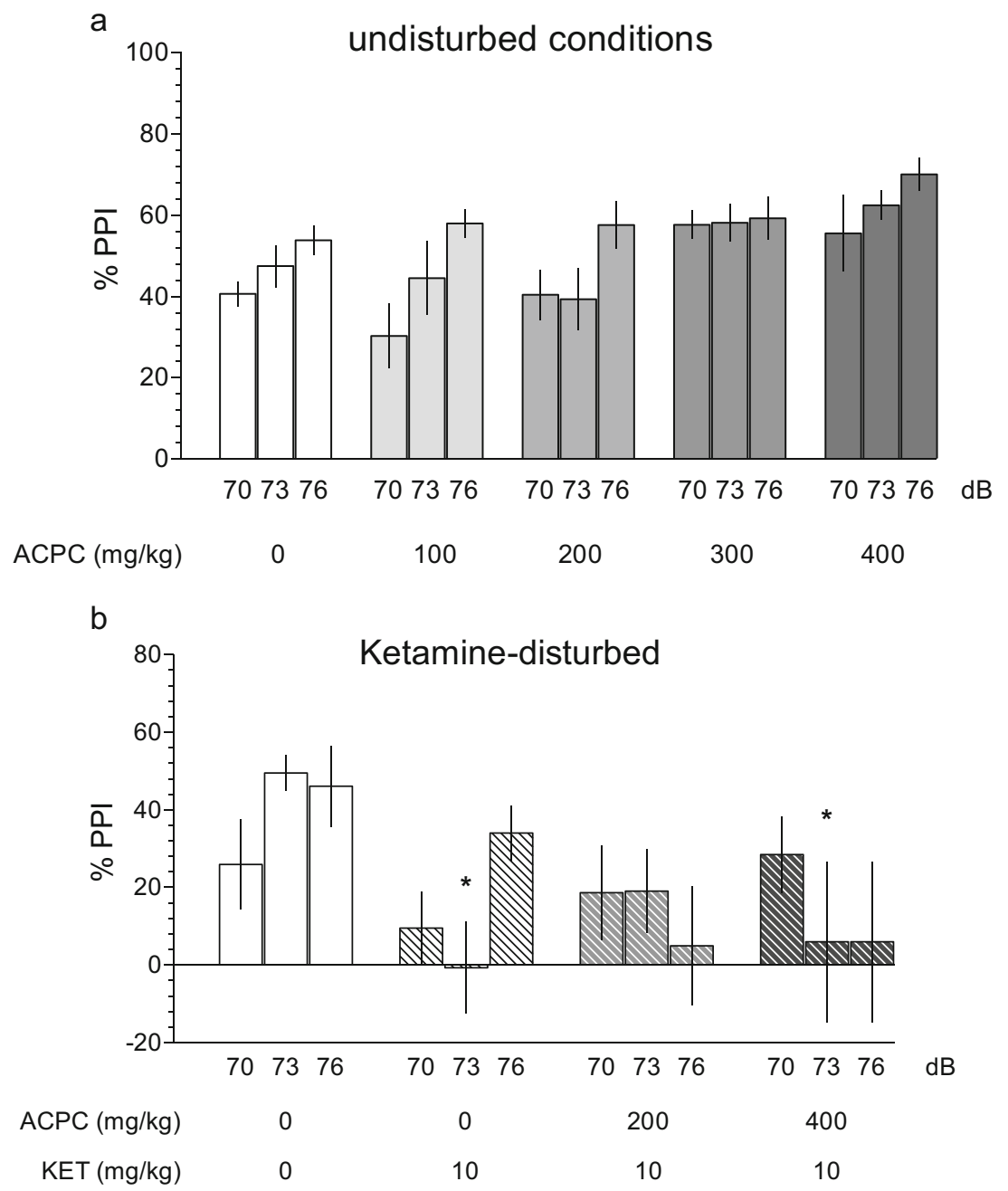

inhibitor, NSFP, improved MK-801-disrupted social memory (Shimazaki et al. 2010) and of Karasawa et al. (2008), who reported that D-serine and NFPS improved learning in the NOR

Table 2 Effects of ACPC, ketamine, and combinations of these compounds on the startle amplitude evoked by a $120-\mathrm{dB}$ pulse tone in rats

\begin{tabular}{ll}
\hline Dose of ACPC & Mean $\pm \operatorname{SEM}(N)$ startle amplitude in naive rats \\
0 & $519.01 \pm 75.54(15)$ \\
100 & $429.87 \pm 68.01(6)$ \\
200 & $911.19 \pm 171.42(7)^{*}$ \\
300 & $580.37 \pm 82.44(6)$ \\
400 & $688.72 \pm 98.58(4)$ \\
& \\
Treatment & Mean $\pm \operatorname{SEM}(N)$ startle amplitude in KET-treated rats \\
VEH-VEH & $557.70 \pm 114.42(6)$ \\
KET-VEH & $618.38 \pm 76.95(11)$ \\
KET-ACPC 200 & $701.8 \pm 138.87(5)$ \\
KET-ACPC 400 & $763.08 \pm 137.65(6)$ \\
\hline
\end{tabular}

$* P<0.05$ vs. vehicle test in conditions disturbed by MK-801 administration. The present data with ACPC demonstrating a similar alleviation of learning disturbances induced by PCP and ketamine in the novel object recognition task, confirm these findings and appear as a logical consequence of its partial agonistic activity at the glycine/NMDA sites.

The present results with ACPC also extend, and are consistent with, our recent findings with a GlyT1 inhibitor (Nikiforuk et al. 2011), demonstrating that increased NMDAR tone may facilitate cognitive flexibility, which is compromised in schizophrenia (Lewis and Gonzalez-Burgos 2008). Because NMDA channel blockers produce symptoms of psychoses (Morris et al. schizophrenia (Coyle et al. 2003), the procognitive effects of ACPC suggest a potential for this type of compound in treating the cognitive deficits associated with psychoses.

\section{Antipsychotic-like effects}

The rationale for studying the potential antipsychotic-like effects of a glycine site partial agonist was based on reports 2005) and NMDARs are hypothesized to be hypoactive in 
Fig. 6 Neither (a) ACPC nor (b) MK-801 affected the accuracy in the five-choice serial reaction time task (5-CSRTT). However, while (c) ACPC did not affect the number of premature responses, a measure of impulsivity, (d) MK801 dose-dependently increased this measure. Values represent the mean $( \pm$ SEM) percentage of premature responses and number of premature responses. $* P<0.05$, vs. vehicle. $N=9-12$ rats per dose (ACPC study) and 7-8 rats per dose (MK-801 study) a

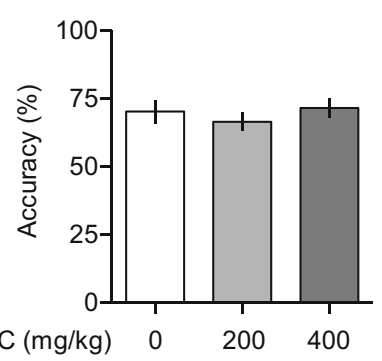

C

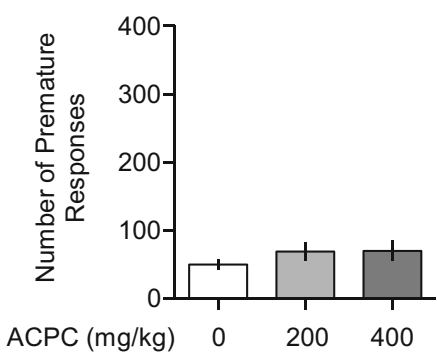

b

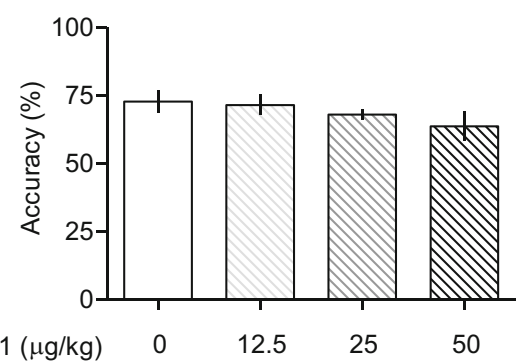

d

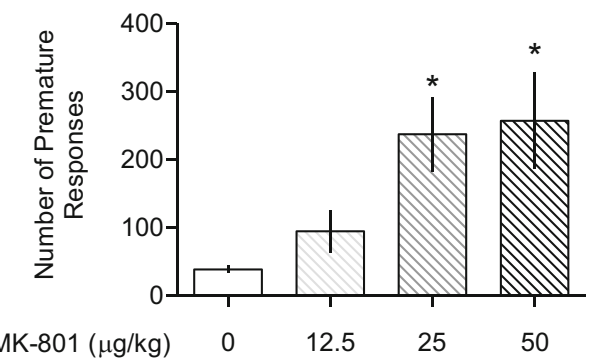

indicating similar actions of glycine full agonists like D-serine, the partial agonist D-cycloserine and GlyT1 inhibitors, already in clinical trials; for a review, see (Harvey and Yee 2013). However, despite using three different tests, we were unable to demonstrate antipsychotic-like effects of ACPC.

Karcz-Kubicha et al. (1999) reported that ACPC $(600 \mathrm{mg} / \mathrm{kg}$ ) enhanced PCP-induced hyperactivity; the effects of lower doses were not investigated. While the lack of efficacy of ACPC in affecting PCP-induced hyperactivity reported here could be due to insufficient dosing, doses $\leq 400 \mathrm{mg} / \mathrm{kg}$ of ACPC produced a number of procognitive effects (Figs. 1 and 2; as well as other therapeutic (antidepressant-like, neuroprotective, anxiolytic) actions (see the "Introduction" section)).

In apparent contrast to Karcz-Kubicha et al. (1999) and the present findings, an enhancement of glycine site function reduces behavioral manifestations associated with NMDA receptor blockade. For instance, glycine transporter inhibitors reversed or attenuated NMDAR antagonist-induced deficits in PPI (Lipina et al. 2005; Depoortere et al. 2005; Boulay et al. 2008), suggesting that stimulation of glycine/NMDA sites leads to antipsychotic-like effects. This is consistent with human data showing that ketamine-induced schizophrenia-
Table 3 Effects of ACPC and MK-801 on omissions (total number of trials omitted during a 100-trial session), correct response latency (time from the stimulus onset to a correct response), reward latency (time from a correct response to the retrieval of food from the magazine), and perseverant responses (total number of responses emitted after a correct response has been made) in the five-choice serial reaction time task. Values represent the mean $( \pm \mathrm{SEM}) . N=9-12$ rats per dose (ACPC study) and 7-8 rats per dose (MK-801 study)

\begin{tabular}{lllll}
\hline Treatment & Omissions $(n)$ & Latency correct $(s)$ & Latency reward $(s)$ & Perseverant $(n)$ \\
\hline Vehicle & $12.9 \pm 2.5$ & $0.96 \pm 0.07$ & $1.73 \pm 0.08$ & $1.6 \pm 0.7$ \\
ACPC $200 \mathrm{mg} / \mathrm{kg}$ & $10.9 \pm 1.6$ & $0.99 \pm 0.08$ & $1.56 \pm 0.13$ & $1.8 \pm 0.8$ \\
ACPC $400 \mathrm{mg} / \mathrm{kg}$ & $11.8 \pm 1.6$ & $0.81 \pm 0.07$ & $1.53 \pm 0.11$ & $2.0 \pm 0.9$ \\
& $F(2.29)=0.27$ & $F(2.29)=1.85$ & $F(2.29)=0.84$ & $\mathrm{NS}$ \\
& $\mathrm{NS}$ & $\mathrm{NS}$ & & $\mathrm{NS}$ \\
Vehicle & & & $1.80 \pm 0.1$ & $3.6 \pm 0.8$ \\
MK-801 $12 \mu \mathrm{g} / \mathrm{kg}$ & $13.5 \pm 2.6$ & $0.93 \pm 0.04$ & $1.46 \pm 0.08^{*}$ & $2.8 \pm 1.4$ \\
MK-801 $25 \mu \mathrm{g} / \mathrm{kg}$ & $8.1 \pm 1.8$ & $0.75 \pm 0.03^{*}$ & $1.47 \pm 0.07^{*}$ & $2.3 \pm 0.8$ \\
MK-801 $50 \mu \mathrm{g} / \mathrm{kg}$ & $13.6 \pm 2.0$ & $0.78 \pm 0.04^{*}$ & $1.39 \pm 0.06^{*}$ & $1.1 \pm 0.7$ \\
& $18.0 \pm 4.9$ & $0.84 \pm 0.04$ & $F(3.27)=4.91$ & $F(3.27)=1.14$ \\
\hline
\end{tabular}

$* P<0.05$, vs. vehicle 
like symptoms were ameliorated by GlyT1 inhibitor Org 25935 in healthy humans (D'Souza et al. 2012). In light of these findings, the lack of efficacy of ACPC in the tests predictive of antipsychotic action could be viewed as unexpected. It should be noted, however, that the present results in the PPI test should be treated with caution. While a significant ketamine-induced disruption of PPI was observed (Fig. 5b), the effects of ketamine were modest compared to other reports (Swerdlow et al. 1998). ACPC at the highest doses of 300 and $400 \mathrm{mg} / \mathrm{kg}$ per se appeared to increase PPI (Fig. 5a), but the statistical analysis did not find these increases significant. Nonetheless, such a purportedly antipsychotic-like effect would not be consistent with the data indicating that neither clozapine, haloperidol, nor chlorpromazine per se increased the PPI response (Swerdlow et al. 1998). Finally, ACPC at a single dose $(200 \mathrm{mg} / \mathrm{kg})$ increased startle amplitude, but this effect was neither related to the dose nor consistent with a purported antipsychotic-like action, as startle amplitude is increased by psychotomimetic compounds like MK- 801 (Bakshi et al. 1994).

ACPC: from an agonist to a functional antagonist at the glycine/NMDA sites

In the presence of saturating concentrations of glutamate, the efficacy of ACPC is high, $90 \%$ relative to glycine (Marvizon et al. 1989; Karcz-Kubicha et al. 1997). However, ACPC was reported to exhibit only $60 \%$ of the glycine's activity in enhancing $\left[{ }^{3} \mathrm{H}\right] \mathrm{MK}-801$ binding in the nominal absence of glutamate (that is, using well-washed brain membranes; (Marvizon et al. 1989)) suggesting a functional antagonist profile dependent upon ambient concentrations of both glutamate and glycine.

These findings may have important therapeutic implications because they suggest that when glutamate concentrations are high, as in learning and memory tasks (Danysz and Parsons 1998), ACPC could display an agonist-like profile, enhancing cognitive processes. In contrast, in the hypoglutamatergic states associated with psychoses (Coyle et al. 2003), ACPC behaves like a functional glycine receptor antagonist and exhibits no antipsychotic-like efficacy.

Clinical studies are consistent with this hypothesis. Thus, while an addition of the partial agonist, D-cycloserine, to risperidone in schizophrenic patients reduced negative symptoms (Evins et al. 2002), meta-analyses showed that glycine site full agonists are more effective than D-cycloserine in improving the overall psychopathology in schizophrenic patients receiving antipsychotic drugs (Heresco-Levy and Javitt 2004; Tuominen et al. 2005; Tsai and Lin 2010). Nonetheless, the recent reports indicating that GlyT1 inhibitors do not improve clinical symptoms of schizophrenia in large, phase III trials (Kingwell 2014) raise serious questions about the viability of glutamate-based approaches to treat schizophrenia. At a minimum, these discrepant findings indicate that not all methods of elevating glycinergic tone produce equivalent results in the clinic. In essence, this raises the bar for preclinical evidence sufficient to trigger clinical studies. Nonetheless, like NMDAR antagonists (Layer et al. 1998), D-cycloserine at relatively high doses, suggestive of NMDAR antagonistic actions, was recently reported to produce an antidepressant effect in treatmentresistant depressed patients (Heresco-Levy et al. 2013). These clinical observations reveal the potential for glycine site partial agonists to mimic the pharmacological actions of both glycine site agonists and antagonists, which is consistent with the present demonstration that ACPC possesses procognitive, but not antipsychotic-like efficacy. Thus, we postulate that a compound with a neurochemical profile like that of ACPC may represent a useful pharmacological approach for cognitive enhancement in domains critically affected in schizophrenia, but would not affect negative or positive symptoms of the psychoses.

Acknowledgments This study was supported by the Statutory Funds of the Institute of Pharmacology, Polish Academy of Sciences. RT is supported by grant SAF2011-23550. The technical help of Dr K. Fijał in performing the PPI experiment is appreciated.

\section{Conflict of interest None}

Open Access This article is distributed under the terms of the Creative Commons Attribution License which permits any use, distribution, and reproduction in any medium, provided the original author(s) and the source are credited.

\section{References}

Amitai N, Markou A (2010) Disruption of performance in the five-choice serial reaction time task induced by administration of N-methyl-Daspartate receptor antagonists: relevance to cognitive dysfunction in schizophrenia. Biol Psychiatry 68:5-16

Auclair AL, Kleven MS, Besnard J, Depoortere R, Newman-Tancredi A (2006) Actions of novel antipsychotic agents on apomorphineinduced PPI disruption: influence of combined serotonin 5-HT1A receptor activation and dopamine D2 receptor blockade. Neuropsychopharmacology 31:1900-1909

Bakshi VP, Swerdlow NR, Geyer MA (1994) Clozapine antagonizes phencyclidine-induced deficits in sensorimotor gating of the startle response. J Pharmacol Exp Ther 271:787-794

Bannerman DM, Butcher SP, Good MA, Morris RGM (1997) Intracerebroventricular infusion of the NMDA receptor-associated glycine site antagonist 7-chlorokynurenate impairs water maze performance but fails to block hippocampal long-term potentiation in vivo. Neurobiol Learn Mem 68:252-270

Bari A, Dalley JW, Robbins TW (2008) The application of the 5-choice serial reaction time task for the assessment of visual attentional processes and impulse control in rats. Nat Protoc 3:759-767

Birrell JM, Brown VJ (2000) Medial frontal cortex mediates perceptual attentional set shifting in the rat. J Neurosci 20:4320-4324 
Black MD, Varty GB, Arad M, Barak S, De Levie A, Boulay D, Pichat P, Griebel G, Weiner I (2009) Procognitive and antipsychotic efficacy of glycine transport 1 inhibitors (GlyT1) in acute and neurodevelopmental models of schizophrenia: latent inhibition studies in the rat. Psychopharmacology 202:385-396

Boulay D, Pichat P, Dargazanli G, Estenne-Bouhtou G, Terranova JP, Rogacki N, Stemmelin J, Coste A, Lanneau C, Desvignes C, Cohen C, Alonso R, Vige X, Biton B, Steinberg R, Sevrin M, Oury-Donat F, George P, Bergis O, Griebel G, Avenet P, Scatton B (2008) Characterization of SSR103800, a selective inhibitor of the glycine transporter-1 in models predictive of therapeutic activity in schizophrenia. Pharmacol Biochem Behav 91:47-58

Carli M, Balducci C, Samanin R (2001) Stimulation of 5-HT1A receptors in the dorsal raphe ameliorates the impairment of spatial learning caused by intrahippocampal 7-chloro-kynurenic acid in naive and pretrained rats. Psychopharmacology 158:39-47

Coyle JT, Tsai G, Goff D (2003) Converging evidence of NMDA receptor hypofunction in the pathophysiology of schizophrenia. Ann N Y Acad Sci 1003:318-327

Danysz W, Parsons CG (1998) Glycine and NMDA receptors - physiological significance and possible therapeutic applications. Pharmacol Rev 50:597-664

Depoortere R, Dargazanli G, Estenne-Bouhtou G, Coste A, Lanneau C, Desvignes C, Poncelet M, Heaulme M, Santucci V, Decobert M, Cudennec A, Voltz C, Boulay D, Terranova JP, Stemmelin J, Roger P, Marabout B, Sevrin M, Vige X, Biton B, Steinberg R, Francon D, Alonso R, Avenet P, Oury-Donat F, Perrault G, Griebel G, George P, Soubrie P, Scatton B (2005) Neurochemical, electrophysiological and pharmacological profiles of the selective inhibitor of the glycine transporter-I SSR504734, a potential new type of antipsychotic. Neuropsychopharmacology 30:1963-1985

D'Souza DC, Singh N, Elander J, Carbuto M, Pittman B, Udo de Haes J, Sjogren M, Peeters P, Ranganathan M, Schipper J (2012) Glycine transporter inhibitor attenuates the psychotomimetic effects of ketamine in healthy males: preliminary evidence. Neuropsychopharmacology 37 : 1036-1046

Duffy S, Labrie V, Roder JC (2008) D-serine augments NMDANR2B receptor-dependent hippocampal long-term depression and spatial reversal learning. Neuropsychopharmacology 33: 1004-1018

Egerton A, Reid L, McKerchar CE, Morris BJ, Pratt JA (2005) Impairment in perceptual attentional set-shifting following PCP administration: a rodent model of set-shifting deficits in schizophrenia. Psychopharmacology (Berl) 179:77-84

Ennaceur A, Delacour J (1988) A new one-trial test for neurobiological studies of memory in rats. 1: behavioral data. Behav Brain Res 31: $47-59$

Evins AE, Amico E, Posever TA, Toker R, Goff DC (2002) DCycloserine added to risperidone in patients with primary negative symptoms of schizophrenia. Schizophr Res 56:19-23

Faiman CP, Viu E, Skolnick P, Trullas R (1994) Differential effects of compounds that act at strychnine-insensitive glycine receptors in a punishment procedure. J Pharmacol Exp Ther 270:528-533

Fijal K, Popik P, Nikiforuk A (2014) Co-administration of 5-HT6 receptor antagonists with clozapine, risperidone, and a 5-HT2A receptor antagonist: effects on prepulse inhibition in rats. Psychopharmacology 231:269-281

Fossom LH, Von Lubitz DKJE, Lin RCS, Skolnick P (1995) Neuroprotective actions of 1-aminocyclopropanecarboxylic acid (ACPC): a partial agonist at strychnine-insensitive glycine sites. Neurol Res 17:265-269

Geyer MA, Krebs-Thomson K, Braff DL, Swerdlow NR (2001) Pharmacological studies of prepulse inhibition models of sensorimotor gating deficits in schizophrenia: a decade in review. Psychopharmacology (Berl) 156:117-154
Gleason SD, Shannon HE (1997) Blockade of phencyclidine-induced hyperlocomotion by olanzapine, clozapine and serotonin receptor subtype selective antagonists in mice. Psychopharmacology (Berl) 129:79-84

Harvey RJ, Yee BK (2013) Glycine transporters as novel therapeutic targets in schizophrenia, alcohol dependence and pain. Nat Rev Drug Discov 12:866-885

Hashimoto K, Malchow B, Falkai P, Schmitt A (2013) Glutamate modulators as potential therapeutic drugs in schizophrenia and affective disorders. Eur Arch Psychiatry Clin Neurosci 263:367-377

Heresco-Levy U, Javitt DC (2004) Comparative effects of glycine and Dcycloserine on persistent negative symptoms in schizophrenia: a retrospective analysis. Schizophr Res 66:89-96

Heresco-Levy U, Gelfin G, Bloch B, Levin R, Edelman S, Javitt DC, Kremer I (2013) A randomized add-on trial of high-dose D-cycloserine for treatment-resistant depression. Int J Neuropsychopharmacol 16:501-506

Higgins GA, Enderlin M, Haman M, Fletcher PJ (2003) The 5-HT2A receptor antagonist $\mathrm{M} 100,907$ attenuates motor and impulsivetype' behaviours produced by NMDA receptor antagonism. Psychopharmacology (Berl) 170:309-319

Howell DC (1997) Statistical methods for psychology. Wadsworth, Belmont

Javitt DC, Zukin SR (1991) Recent advances in the phencyclidine model of schizophrenia. Am J Psychiatry 148:1301-1308

Javitt DC, Zylberman I, Zukin SR, Heresco-Levy U, Lindenmayer JP (1994) Amelioration of negative symptoms in schizophrenia by glycine. Am J Psychiatry 151:1234-1236

Jentsch JD, Roth RH (1999) The neuropsychopharmacology of phencyclidine: from NMDA receptor hypofunction to the dopamine hypothesis of schizophrenia. Neuropsychopharmacology 20:201-225

Johnson JW, Ascher P (1987) Glycine potentiates the NMDA response in cultured mouse brain neurons. Nature 325:529

Karasawa JI, Hashimoto K, Chaki S (2008) D-Serine and a glycine transporter inhibitor improve MK-801-induced cognitive deficits in a novel object recognition test in rats. Behav Brain Res 186:78-83

Karcz-Kubicha M, Jessa M, Nazar M, Plaznik A, Hartmann S, Parsons CG, Danysz W (1997) Anxiolytic activity of glycine-B antagonists and partial agonists - no relation to intrinsic activity in the patch clamp. Neuropharmacology 36:1355-1367

Karcz-Kubicha M, Wedzony K, Zajaczkowski W, Danysz W (1999) NMDA receptor antagonists acting at the glycineB site in rat models for antipsychotic-like activity. J Neural Transm 106:1189-1204

Kingwell K (2014) Schizophrenia drug gets negative results for negative symptoms. Nat Rev Drug Discov 13:244-245

Kolesnikov YA, Maccecchini M-L, Pasternak GW (1994) 1Aminocyclopropanecarboxylic acid (ACPC) prevents mu and delta opioid tolerance. Life Sci 55:1393-1398

Krystal JH, Karper LP, Seibyl JP, Freeman GK, Delaney R, Bremner JD, Heninger GR, Bowers MB, Charney DS (1994) Subanesthetic effects of the noncompetitive NMDA antagonist, ketamine, in humans. Psychotomimetic, perceptual, cognitive, and neuroendocrine responses. Arch Gen Psychiatry 51:199-214

Lane HY, Chang YC, Liu YC, Chiu CC, Tsai GE (2005) Sarcosine or Dserine add-on treatment for acute exacerbation of schizophrenia: a randomized, double-blind, placebo-controlled study. Arch Gen Psychiatry 62:1196-1204

Layer RT, Popik P, Nowak G, Paul IA, Trullas R, Skolnick P (1998) A unified theory of antidepressant action: evidence from adaptation of the N-methyl-D-aspartate (NMDA) receptor complex following chronic antidepressant treatments. In: Soria B, Cena V (eds) Ion channel pharmacology. Oxford University Press, London, pp 438-457

Lewis DA, Gonzalez-Burgos G (2008) Neuroplasticity of neocortical circuits in schizophrenia. Neuropsychopharmacology 33:141-165

Lipina T, Labrie V, Weiner I, Roder J (2005) Modulators of the glycine site on NMDA receptors, D-serine and ALX 5407, display similar 
beneficial effects to clozapine in mouse models of schizophrenia. Psychopharmacology (Berl) 179:54-67

Marvizon JC, Lewin AH, Skolnick P (1989) 1-Aminocyclopropane carboxylic acid: a potent and selective ligand for the glycine modulatory site of the N-methyl-D-aspartate receptor complex. J Neurochem 52:992-994

Monahan JB, Handelmann GE, Hood WF, Cordi AA (1989) Dcycloserine, a positive modulator of the NMDA receptor, enhances learning and memory in rats. Pharmacol Biochem Behav 34:649-665

Morris BJ, Cochran SM, Pratt JA (2005) PCP: from pharmacology to modelling schizophrenia. Curr Opin Pharmacol 5:101-106

Nikiforuk A, Golembiowska K, Popik P (2010) Mazindol attenuates ketamine-induced cognitive deficit in the attentional set shifting task in rats. Eur Neuropsychopharmacol 20:37-48

Nikiforuk A, Kos T, Rafa D, Behl B, Bespalov A, Popik P (2011) Blockade of glycine transporter 1 by SSR-504734 promotes cognitive flexibility in glycineB/NMDA receptor-dependent manner. Neuropharmacology 61:262-267

Nikiforuk A, Fijal K, Potasiewicz A, Popik P, Kos T (2013) The 5hydroxytryptamine (serotonin) receptor 6 agonist EMD 386088 ameliorates ketamine-induced deficits in attentional set shifting and novel object recognition, but not in the prepulse inhibition in rats. J Psychopharmacol 27:469-476

Papp M, Moryl E (1996) Antidepressant-like effects of 1aminocyclopropanecarboxylic acid and D-cycloserine in an animal model of depression. Eur J Pharmacol 316:145-151

Popik P, Rygielska Z (1999) A partial agonist at strychnine-insensitive glycine sites facilitates spatial learning in aged rats. J Physiol Pharmacol 50:139-151

Pussinen R, Sirvio J (1999) Effects of D-cycloserine, a positive modulator of N-methyl-D-aspartate receptors, and ST 587, a putative alpha-1 adrenergic agonist, individually and in combination, on the nondelayed and delayed foraging behaviour of rats assessed in the radial arm maze. J Psychopharmacol 13:171-179

Raiteri L, Raiteri M (2010) Functional 'glial' GLYT1 glycine transporters expressed in neurons. J Neurochem 114:647-653

Shimazaki T, Kaku A, Chaki S (2010) D-Serine and a glycine transporter1 inhibitor enhance social memory in rats. Psychopharmacology 209:263-270

Singer P, Feldon J, Yee BK (2009) The glycine transporter 1 inhibitor SSR504734 enhances working memory performance in a continuous delayed alternation task in C57BL/6 mice. Psychopharmacology (Berl) 202:371-384

Stefani MR, Groth K, Moghaddam B (2003) Glutamate receptors in the rat medial prefrontal cortex regulate set-shifting ability. Behav Neurosci 117:728-737

Swerdlow NR, Bakshi V, Waikar M, Taaid N, Geyer MA (1998) Seroquel, clozapine and chlorpromazine restore sensorimotor gating in ketamine-treated rats. Psychopharmacology (Berl) 140:75-80

Toth E, Lajtha A (1986) Antagonism of phencyclidine-induced hyperactivity by glycine in mice. Neurochem Res 11:393-400

Trullas R, Skolnick P (1990) Functional antagonists at the NMDA receptor complex exhibit antidepressant actions. Eur J Pharmacol 185:1-10

Trullas R, Jackson B, Skolnick P (1989) Anxiolytic properties of 1aminocyclopropanecarboxylic acid, a ligand at strychnineinsensitive glycine receptors. Pharmacol Biochem Behav 34:313-316

Trullas R, Folio T, Young A, Miller R, Boje K, Skolnick P (1991) 1Aminocyclopropanecarboxylates exhibit antidepressant and anxiolytic actions in animal models. Eur J Pharmacol 203:379-385

Tsai GE, Lin PY (2010) Strategies to enhance N-methyl-D-aspartate receptor-mediated neurotransmission in schizophrenia, a critical review and meta-analysis. Curr Pharm Des 16:522-537

Tuominen HJ, Tiihonen J, Wahlbeck K (2005) Glutamatergic drugs for schizophrenia: a systematic review and meta-analysis. Schizophr Res 72:225-234

Viu E, Zapata A, Capdevila J, Skolnick P, Trullas R (2000) Glycine(B) receptor antagonists and partial agonists prevent memory deficits in inhibitory avoidance learning. Neurobiol Learn Mem 74:146160

Von Lubitz DKJE, Lin RCS, McKenzie RJ, Devlin TM, McCabe RT, Skolnick P (1992) A novel treatment of global cerebral ischaemia with a glycine partial agonist. Eur J Pharmacol 219:153-158

Wadenberg ML, Hicks PB (1999) The conditioned avoidance response test re-evaluated: is it a sensitive test for the detection of potentially atypical antipsychotics? Neurosci Biobehav Rev 23:851-862

Wadenberg ML, Young KA, Trompler RA, Zavodny RA, Richter TJ, Hicks PB (1997) A novel computer-controlled conditioned avoidance apparatus for rats. J Pharmacol Toxicol Methods 38:211-215

Witkin JM, Tortella FC (1991) Modulators of N-methyl-D-aspartate protect against diazepam- or phenobarbital-resistant cocaine convulsions. Life Sci 48:L51-L56 